\title{
Remembering, Forgetting, and Absencing Disasters in the Post- disaster Recovery Process
}

\author{
Charlotte Monteil $^{1} \cdot$ Jenni Barclay $^{2} \cdot$ Anna Hicks $^{3}$
}

Published online: 20 May 2020

(C) The Author(s) 2020

\begin{abstract}
Sustainable post-disaster recovery implies learning from past experience in order to prevent recreating forms of vulnerability. Memory construction supports both the healing process and redevelopment plans. Hence, memory of disaster results from the balance between remembering, forgetting, and absencing elements of the disaster, and can be both a tool and an obstacle to sustainable recovery. We explore here how collective memory is built in a post-disaster context to respond to the needs of this critical period, and how it shapes recovery. This ethnographic study, conducted between 2015 and 2017, explores the recovery processes in Montserrat, a small Caribbean island affected by an extended volcanic crisis from 1995 to 2010. Although this study does not give tangible solutions for disaster risk reduction in a post-disaster context, it highlights potential obstacles for learning from a disaster and how they may be surmounted. We argue that it is crucial to acknowledge evolving collective memory in order to implement effective measures for preserving and sharing a shared understanding of disaster across generations and social groups in a way that supports disaster risk awareness. We also maintain that acknowledging the dilemma faced by authorities and disaster management agencies during a period of conflicting needs may encourage the reconsideration of risk framing, and
\end{abstract}

Charlotte Monteil

c.monteil@lancaster.ac.uk

1 Lancaster Environment Center, Lancaster University, Bailrigg LA1 4YW, UK

2 School of Environmental Sciences, University of East Anglia, Norwich NR4 7TJ, UK

3 Edinburgh Office, British Geological Survey, Edinburgh EH14 4BA, UK hence reveal how to improve implementation of disaster risk reduction measures.

Keywords Absencing risk information - Disaster remembering . Forgetting processes $\cdot$ Montserrat $\cdot$ Postdisaster recovery

\section{Introduction}

While post-disaster recovery processes result from strategies informed by risk perceptions and visions of the future, they are strongly influenced by experience and memory of disaster. Remembering a disaster also goes hand in hand with the process of forgetting about it. Acknowledging the now well-recognized fact that disasters are largely a social construct (Mileti 1999; Wisner et al. 2004; Kelman 2020), this article explores the idea that there is much more that can be learned from what is forgotten after a disaster. More than being just elements that are not worth remembering from the disaster, they can be the result of an active exercise, combining strategies for absencing, or silencing some elements of the past, present, and future. This can be a response to some specific needs, conscious or unconscious.

Although studies on memory following a crisis tend to focus on individual memories and their association with trauma (Kevers et al. 2016) and on memorialization (Le Blanc 2012), little attention has been given to the role of the process of remembering, forgetting, and absencing in the post-disaster context and on its influence on the recovery process. Yet this period is critical for implementing strategies and processes that can increase the longterm sustainable development of communities, even in the face of further hazardous events. However, this long-term 
strategy needs to be balanced with the need for quick response (Olshansky et al. 2012) to the socioeconomic and physical damages linked to the disaster, which makes longterm perspectives on decision making very challenging (Monteil et al. 2020). In the context of disaster risk, the processes of remembering and forgetting contribute to individual and institutional strategies implemented to prepare for future risks and learn from past disasters. Importantly, forgotten elements can re-emerge involuntarily when reminders arise and can impact future actions, negatively or positively (Oliver-Smith et al. 2016).

This study contributes to our understanding of how experiential learning is absorbed by populations at risk and how this impacts on future actions. This study, instead of analyzing the state of collective memory in a post-disaster context, aims to examine the conscious and unconscious strategies implemented during the post-disaster recovery process and examine how they appear to shape collective memory, in order to explore how preparedness measures might be improved during recovery. We analyze the institutional strategies for forgetting risks implemented during a post-disaster period, and explore how this forgetfulness shapes recovery processes and their sustainability. We argue that while silencing the risk of disaster is part of a strategy to support some dimensions of the recovery process, it can prevent sustainable recovery by hindering the learning process.

The study is illustrated by the recovery process in Montserrat, a small Caribbean island affected by an extended volcanic crisis from 1995 to 2010 . We first review the current understanding of the recovery process and of the role of remembering and forgetting in this context. We then analyze them in the context of Montserrat and demonstrate how active forgetting efforts impede learning from disaster. This study brings some original aspects to the field of disaster risk science we exploring the topic through remembering, forgetting, and absencing. We approach the recovery of Montserrat from a new and longitudinal perspective, an aspect lacking in much work that covers this volcanic eruption (and many other disasters) from social science perspectives.

\section{Post-disaster Recovery: Creating Collective Memory in Order to Move Forward}

While the direct experience of a disaster becomes part of the history of those affected, the way it is translated into memory can be highly variable. In the long term, the memory of the disaster is what remains from the disaster and is thought to create risk awareness in those who have been previously affected. Several studies have explored how disasters were materialized in order to create a collective memory (Le Blanc 2012). It is the collective dimension of these representations that is particularly important as it contributes to the shaping of power relationships and institutional decisions (Halbwachs 1950). These are critical to long-term development, as much as collective memory is constructed by these decisions. Yet as Le Blanc (2012) suggested, the link between risk perception and memory of disaster is not straightforward. To appreciate this complexity, it is crucial to understand what memory is and what the processes of remembering and forgetting are.

\subsection{Remembering the Experience of Disaster}

Halbwachs (1950) was the first to explicitly conceptualize collective (also called cultural) memory. In particular, he argued that individual memories are inherently shaped, often also triggered, by the sociocultural context. More recently, Erll and Nunning (2008, p. 2) defined cultural memory as "the interplay of present and past in sociocultural contexts." They underlined that although society does not literally remember, the process implemented to reconstruct a shared past is similar to the one implemented for individual memory. They emphasized that the understanding of cultural memory should be multidisciplinary and involves social, medial, and cognitive processes, and their continuous interactions. The field has recently expanded into personal trauma after a crisis such as war (Suleiman 2012; Isakson and Jurkovic 2013; Kevers et al. 2016). The critical finding from these works is that memory is a social construction (Conway 2003). Erll and Nunning (2008, p. 7) explain that "the past is not given, but must be continuously re-constructed and re-presented." Sociologists claim that representations of the past are maintained through specific social practices, and are created by the interactions between people in a specific societal context (Conway 2003; Connerton 2010). Therefore, the memory of an identical event can be very variable depending on the individuals, groups, or/and periods. Legg (2007, p. 459) summarizes: "collective memory is a narrative that excludes rival interpretations and is thus haunted by the potential to remember differently or to refuse to forget." Similarly this narrative can be used as a tool for empowering or silencing groups in differing social contexts (Jackson 2002), and so what is remembered can shift with the conscious or unconscious objectives of those sharing, in ways that may not directly relate to the factual context. Although the concept of memory remains quite controversial, as some scholars argue that it is too vague and broad (Conway 2003), it nonetheless largely contributes towards an explanation of the construction of identity (Conway 2003) and of post-disaster recovery. 


\subsection{The Role of Forgetting in Memory}

By its very nature, the process of remembering induces a selection and implies that elements of our past are forgotten in the meantime. Suleiman (2012) points out that forgetting is an active agent in the formation of memory. Halbwachs and Coser (1992) first brought up the idea by stating that remembrances often aim to meet some specific needs. Implicitly, it means that some elements are voluntarily pushed away as they do not correspond to these objectives. Halbwachs and Coser (1992, p. 51) argue that "the mind reconstructs its memory under the pressure of the society," forgetting the constraints of the past as they no longer operate, and adapting the memory to the framework of present. Memory helps to shape the vision of the present and the desires for the future, but is also shaped by them at the same time (Halbwachs and Coser 1992; Hamer 1994); this interactive process leads to diverse and evolving memories. Academic literature has recently started to address the forgetting process through research on selective remembering (Hoelscher and Alderman 2004; Legg 2007; Johnson 2012; Muzaini 2015).

The process of active forgetting has been explored through different disciplines, in particular psychology (Hardt et al. 2013), neuroscience (Singer and Conway 2008), and social anthropology. Connerton (2008) distinguished seven types of forgetting that play different functions and that are implemented by different types of agents. They include: (1) repressive erasure, as a condemnation of memory with or without violence; (2) prescriptive forgetting, seen as beneficial for all parties involved; (3) forgetting that is constitutive in the formation of a new identity; (4) structural amnesia; (5) forgetting as annulment because of the surfeit of information; (6) forgetting as planned obsolescence; and (7) forgetting as humiliated silence. Singer and Conway (2008) stressed that this approach neglects the difference between availability and accessibility of memory. They highlighted that they "prefer to talk about the concept of relative degrees of accessibility than to speak in terms of information being truly lost or forgotten" (Singer and Conway 2008, p. 280). In this critique, there is the idea that there is no proper forgetting, and what is forgotten can actually be revived through some specific reminders. Yet some measures can also be implemented to decrease the degree of accessibility of the information and hence encourage their forgetting. We refer to this as "absencing."

A few studies have focused on the role of silencing or absencing information in order to forget it. Muzaini (2015, p. 102) argues that forgetting involves "active embodied, material and spatial practices of producing absences." $\mathrm{He}$ distinguishes three ways of supporting individual forgetting: conspiring silences, enacting absences, and embodying avoidance. Conspiring silences refers to the avoidance of talk about the past in order to prevent its impact on the present. Enacting absences corresponds to the fact of hiding or rearranging some elements of the past in order to manipulate the material world and manage troubling memories. Finally, embodying avoidance highlights the strategy of avoiding certain places to avoid unwanted reminders. More specifically, Bickerstaff and Simmons (2009) and Parkhill et al. (2010) explore how the practice of absencing the risk of disaster in daily life enables living in close physical proximity with technological risk. This practice supports an apparent acceptance of the risk. It can contribute to forgetting the risk in daily life, or more generally to transforming the risk perception.

Parkhill et al. (2010), however, stress that acceptance of and familiarity with risk is transitory and can change dramatically under the influence of some reminders. Although it is explained differently, the studies of Parkill et al. (2010) and Bickerstaff and Simmons (2009) converge with Singer and Conway (2008) in the sense that although there is not a proper forgetting of the risk, individuals decrease their risk perception by absencing it, and hence by lowering the access to information about risks. In the context of everyday risk calculations, it may be that individuals do not perceive some natural hazards as a potential risk, as they are relatively less important on that timescale. Although it diminishes anxiety level in daily life, it can impact decision making for individual and societal long-term development where preparedness for the impacts of occasional hazardous events becomes more important. This "absencing" of lower frequency events can be driven by a lack of direct experience, by an active drive to minimize those risks, or by subconscious processes of forgetting the severity of outcomes or consequence.

Although different practices enable individuals to push away risks and to forget elements of the past, reminders of various shapes can create memory returns (Bickerstaff and Simmons 2009; McEwen et al. 2017). Muzaini (2015, p. 105) explains that "memory returns can be incited when that silence is broken, when what was hidden is found or when one encounters what one has learnt to avoid." Absencing information or facts is therefore not enough to totally forget (Muzaini 2015). In terms of risk perception, direct (for example, witnessing a natural hazard) and indirect experiences (for example, information from others, education, and media) play a major role in recalling previous disaster and hence presence the risks again (Wachinger et al. 2013). Through their study on perception of nuclear risk, Bickerstaff and Simmons (2009, p. 868) argue that "risks $[\ldots]$ nonetheless retain a lingering (if fleeting) presence and a capacity to return. We see precisely these themes of haunting and return in the findings of other local studies of risk experience, which hint at the 
potential for exploring the ghostly remains and reminders of past presences-both places and times-which mediate personal and collective relations with risk." Reminders point out that memory is continually transforming. What appears as forgotten at some point of time can re-emerge later under the pressure of reminders.

\section{Methodology and Case Study}

In order to address the role of remembering and forgetting risks in the post-disaster recovery process, we have explored the memory construction process in Montserrat, a British overseas territory located in the Caribbean (Fig. 1).

\subsection{Case Study}

The study was conducted in Montserrat, whose population was severely affected by a prolonged volcanic eruption from 1995 to 2010. The first eruption occurred only six years after Hurricane Hugo, which devastated about $90 \%$ of the island's infrastructure. The Soufrière Hills volcano, located in the south of the country, became active after several centuries of dormancy. Since 1996, the southern two-thirds of the country have been totally evacuated and remain an exclusion zone. Pyroclastic flows and lahars emanating from the volcano destroyed the capital city, Plymouth, and most of the island's major infrastructure. The last significant activity occurred in 2010, but the volcano is still active with a low level of risk of eruption (SAC 2013). The island is also exposed to a range of other natural hazards, including hurricanes, droughts, tsunamis, landslides, and earthquakes. The island is divided into different zones defined by the level of risk. Most of the previously occupied areas are in the exclusion zone (zone V), with the exception of a few villages in the western side of Montserrat, which are accessible by day (zone C), and are now under consideration for reoccupation. Zones A and B are still occupied and now fully accessible (Montserrat Volcano Observatory and Disaster Management Coordination Agency 2014) (Fig. 2).

In addition to the complete displacement of the population, Montserrat has been subject to major demographic, sociocultural, and economic change during and after the volcanic eruptions. The population decreased from about 10,300 in 1995 to 2700 in 1998 , and finally stabilized around 4500 since 2001, due to rapid and intense immigration of labor from neighboring countries. The rapidity and extent of the post-disaster change perpetuates the sense of disturbance caused by the disaster and affects the recovery trajectory. It also implies that experiences of disaster are both direct, for local policymakers and most
Montserratians, and indirect for new immigrants and younger people.

At the time of the study, there were no immediate plans for reoccupation of the south of Montserrat, but some areas closer to the volcano had been declared safe for general occupation, although amenities (electricity, water, and so on) were not being restored. Since 2015, a few private and collective initiatives were taken to reoccupy some of these areas, including the restoration of some houses, the development of farms and an annual festival gathering of the former residents. Two major industries, sand mining and geothermal activities, are also actively occupying areas formerly evacuated.

\subsection{Research Design}

This research analyzes the post-disaster recovery processes in Montserrat, using an ethnographic-based approach. In addition to a review of academic and grey literature, the research includes ethnographic observation with detailed field notes, in-depth semistructured and informal interviews and four focus group discussions (FGD). All data were collected in Montserrat. A total of 130 interviews were conducted between 2015 and 2017 with government officers, risk management institutions, private entrepreneurs, and residents from the four main nationality groups-Montserratians, Guyanese, Jamaicans, and Dominicans (Table 1).

The interviews were conducted in English or in Spanish and lasted between $20 \mathrm{~min}$ and $1.5 \mathrm{~h}$. The FGD were conducted with Montserratians, Guyanese, and Jamaicans in English and lasted about $1.5 \mathrm{~h}$. Data collection was conducted by an outsider, a white female researcher, and interpreted in the light of this possible bias. All data were anonymized. Qualitative data were then coded in NVivo, using thematic and theoretical codes, in order to be analyzed. The main findings of the study were presented on four occasions during public presentations, both in Montserrat and in the office of the Montserratian government in London, as an opportunity to discuss the findings and open a dialogue with decision makers and residents of the country.

\section{Findings and Discussion}

The research data show that 15 years of eruption have left society on Montserrat with a very ambiguous relationship with risks and disaster. While the 15 years of eruptions have become part of the Montserratian identity and history, the need to psychologically recover and move forward from the disaster leads to a reliance on memory for disaster 


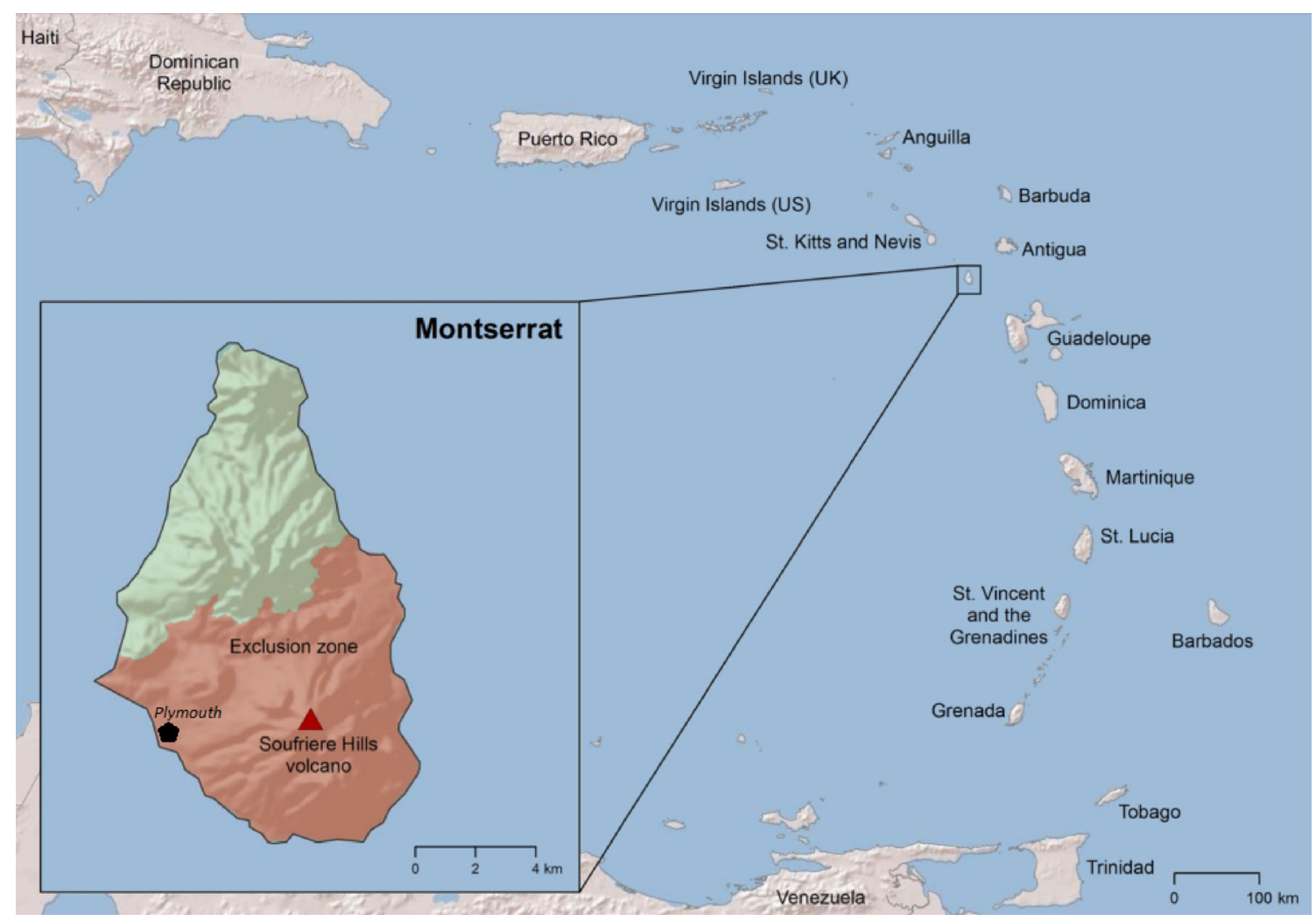

Fig. 1 Montserrat (inset) and its position within the wider Caribbean region. Source: Wilkinson (2015)

preparedness and an absencing of risk in daily life. That process highlights the contradiction faced during the postdisaster recovery process and the challenges for learning from the disaster in order to reduce people's vulnerability.

\subsection{Memory Building Shaped by the Recovery Narratives}

The post-disaster recovery period is dedicated to rebuilding what has been altered by the disaster, better than before, while addressing long-term needs of sustainable development. This includes the need to address the root causes of vulnerability to disaster by learning from previous experiences (López-Carresi 2013). Hence the role of memory building is twofold. On the one hand, it acts as coping strategy to face the trauma of the disaster, and on the other, it supports a narrative that shapes the development trajectory of the affected place (Mika and Kelman 2019).

Yet, several studies have highlighted that there is no straightforward link between risk awareness, experience, and preparedness (Wachinger and Renn 2010; Wachinger et al. 2013). This means that the experience of a disaster is not sufficient to encourage better preparedness measures or better awareness of risks, hence disaster exposure cannot be considered as a sufficient learning process to reduce vulnerability. The way memory is built, and especially what is forgotten, determines a lot of the resulting longterm, transgenerational perception of disaster and risks. Memory construction faces two specific challenges: (1) keeping communities risk-aware and risk-informed while not generating knowledge fatigue; and (2) the balancing low probability possible hazards with shorter time-scale imperatives to regenerate the island.

Through the analysis of the recovery processes in Montserrat following 15 years of eruptions, we highlight major drivers of memory construction. The interviews conducted between 2015 and 2017 reveal how memory is built, and in particular expose some contrasting perceptions related to the level of awareness and knowledge of risk of disaster linked to volcanic hazards.

\subsubsection{Assumed Memory and Knowledge}

Memory construction in post-disaster contexts is a relatively new concern (Convery et al. 2014; Pfefferbaum et al. 2007). Like in most places, in Montserrat memory construction is hardly a dimension of the recovery process that is thought about. Interviews with policymakers and disaster management agencies' officers demonstrate that memory is considered as an inherent component of the recovery process, although officials recognize that some actions can play a reminding role and hence contribute to build a 


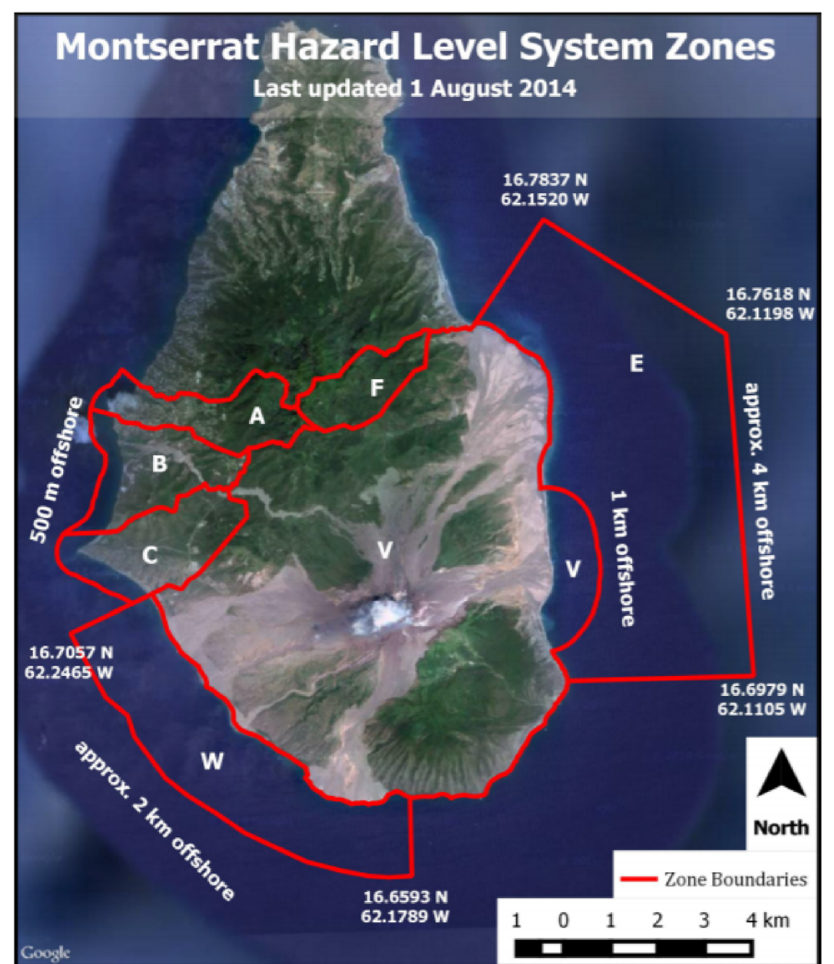

Fig. 2 Montserrat Hazard Level System Zones. Zones A and B are fully accessible. Zones $\mathrm{C}$ and $\mathrm{F}$ are accessible during daytime only. Zone $\mathrm{V}$ is fully restricted except for essential workers. Zones $\mathrm{E}$ and $\mathrm{W}$ are maritime zones, respectively with restricted access to essential workers and daytime access. Source: Montserrat Volcano Observatory and Disaster Management Coordination Agency (2014) memory. Overall, the experience of the disaster is mostly considered as sufficient to build memory of disaster, with little consideration for the elements of risk and disaster that are either absenced or more naturally forgotten. Disaster managers even explained during interviews that they faced difficulties in addressing the risk of disaster with the residents of Montserrat, despite the importance of the disaster in the Montserratian identity and recent history. By contrast, people are generally happy to talk about their memory of the disaster, but more reluctant to tolerate facing the same situation again. Such difference may express discomfort and anxiety regarding the ongoing risks and the attitude needed to face them. Although policymakers admit doubts about what people actually know, the way they address memory construction is mainly led by a collective need for stability and certainty about the future. There is therefore a collective effort to anchor the disaster in the past that takes little or no consideration of the potential implications for post-disaster learning.

When asked about the level of preparedness of the residents of Montserrat, three disaster managers of the two main disaster risk reduction (DRR) organizations and almost all policymakers first argued that residents remember enough from their experience of the disaster to be able to prepare for another disaster. Regarding their level of knowledge of ash falls, a senior policymaker explained in May 2016:

Table 1 Interviews conducted between 2014 and 2017 in Montserrat. The members of risk management, social/health institutions, and business people (categories 2, 3,4) were both Montserratians and non-Montserratians

\begin{tabular}{|c|c|c|c|c|c|c|c|}
\hline & Institutions/groups & $\begin{array}{l}\text { Total number of } \\
\text { interviews }\end{array}$ & $\begin{array}{l}\text { Formal } \\
\text { interviews } \\
\text { (number) }\end{array}$ & $\begin{array}{l}\text { Informal } \\
\text { interviews } \\
\text { (number) }\end{array}$ & Women & Men & $\begin{array}{l}\text { Age range } \\
\text { (estimation) }\end{array}$ \\
\hline 1 & $\begin{array}{l}\text { Government officers (British and } \\
\text { Montserratian government) }\end{array}$ & 21 & 21 & & 9 & 12 & $30-60$ \\
\hline 2 & $\begin{array}{l}\text { Risk management/monitoring institutions } \\
\text { (DMCA, MVO, Red Cross) }\end{array}$ & 10 & 10 & & 5 & 5 & $30-60$ \\
\hline 3 & $\begin{array}{l}\text { Social/Health/Educational institutions (like } \\
\text { social services, schools, churches) }\end{array}$ & 16 & 16 & & 12 & 4 & $30-65$ \\
\hline 4 & Business people & 5 & 5 & & 2 & 3 & $25-55$ \\
\hline 5 & Montserratians & 20 & 8 & 12 & 7 & 13 & $20-75$ \\
\hline 6 & Guyanese & 14 & 8 & 6 & 8 & 6 & $15-65$ \\
\hline 7 & Jamaicans & 14 & 6 & 8 & 6 & 8 & $20-65$ \\
\hline 8 & Dominicans (DR) & 12 & 7 & 5 & 5 & 7 & $45-70$ \\
\hline \multirow[t]{2}{*}{9} & Other nationalities & 18 & 3 & 15 & 4 & 14 & $30-60$ \\
\hline & Total & 130 & 84 & 46 & 58 & 72 & \\
\hline
\end{tabular}

Interviewee nationality was not specifically asked for in the interview as these individuals were interviewed because of their particular task and job. The interviewees in categories $5,6,7,8,9$ were specifically chosen because of the national group with which they identify 
Anybody who has been here for more than 10, for more than five years, six years, knows about the ashing. So they know that, and that's probably the most likely thing that can happen [for] the volcano in the next little while, we can get some ashing of that sort again.

Implicitly, the interviewees addressed the case of Montserratians and immigrants who have lived on the island for a long time. Among the evidence that policymakers present to certify people's awareness of volcanic risk, there is the collective narrative stating that Montserratians are all "a bit of volcanologist" because of their extensive knowledge of scientific vocabulary and volcanic processes. Moreover, reminders such as the volcano, the smell of sulphur, and the presence of an exclusion zone, are also considered as sufficient to preserve the memory of disaster. In January 2016, a disaster manager explained that people living close to the exclusion zone are fully aware of the risk of disaster, "considering that they are in that area, they are constantly reminded of it."

Yet, important nuances emerged when disaster managers and policymakers were asked more specifically about the sufficiency of memory and experience to make the population aware about risks. Initially, they did not make experiential or demographic distinctions in their statements about knowledge, preparedness, and action relating to volcanic risk.

Policymaker: "They know, they know. People absolutely know that [the volcano] can explode any time." Interviewer: "Do you think that non-national people also know?"

Policymaker: "Well, I hope so... but that's a very good question. That's a very, very good question. [...] because if you have not been through it, you don't know what the consequences are." (Interview with a policymaker in May 2016)

Similarly, a teacher affirmed in February 2016 that youths were not able to relate to a film clip on the volcanic disaster. These two people highlight the variations in memory between different social groups. Youths who were born during or after the disaster, and immigrants who did not experience the evacuation, do not share the same memory of the catastrophe. They also do not have the same emotional relationship with the disaster and the predisaster status of the island.

These testimonies emphasize the fluidity of memory among the whole population (Halbwachs and Coser 1992; Connerton 2010). Memory differs among the different social and age groups, depending on their needs to move forward and recover economically and psychologically. When local authorities disproportionately represent a particular demographic group (Montserratian with direct experience of the eruption), however, these different memories are not taken into consideration. Although previous work has shown the complex role of experience on risk awareness and decisions to act for preparedness (Wachinger et al. 2013), policymakers continue to rely on memory for preparedness to disaster during the recovery period.

\subsubsection{Why Rely on Memory for Preparedness and Post- Disaster Learning?}

Questioning memory construction implies challenging multiple post-disaster recovery needs, which all have different degrees of emergency (Olshansky et al. 2012) that can often conflict with each other. This study highlights how the prioritization of recovery objectives is conducted in the context of exposure to several natural hazards and uncertainty of risk of disaster. In Montserrat, the way memory construction is approached is determined on the one hand by the need for stability resulting from the crisis trauma, and on the other, by the risk uncertainty and unfinished status of the crisis. This highlights the considerable challenges in balancing risk awareness against knowledge fatigue while simultaneously mitigating low probability hazards and regenerating the island.

\subsubsection{Need for Stable Psychological, Economic, Demo-} graphic, and Social Recovery The risk of disaster linked to volcanic hazards highlights the persistence of uncertainties regarding the future, and hence the need to take adequate measures to prepare. Yet a sense of safety and stability is needed to provide residents and policymakers with the ability to plan their development by consciously learning from the volcano disaster and taking into consideration the continuing risks. In Montserrat, the need for stability and sense of control following the disaster contributes to risk absencing as a strategy to cope with the fatigue and trauma of the disaster. Interviews with Montserratians and policymakers reveal that the population remains strongly affected by the changes from 15 years of crisis and displacement of $75 \%$ of the population to locations off the island. On several occasions, current inhabitants mention during their interviews the fatigue induced by lack of stability, as well as their need to regain a sense of control, both for psychological and economic purposes. When asked what she would do if there was another eruption, a woman angrily said in 2017: "we can't [deal with an eruption again], we had too much."

Such reaction was very common through the discussions with Montserratians. During an interview in May 2016, a policymaker highlighted the dilemma authorities face when it comes to disaster preparedness: "[the people] don't want 
to hear anything about [the volcanic risk] because they've been exhausted about [it]." Ignoring risks is a way to protect the society and the individual against unmanageable anxiety and preserve ontological security, that is, a sense of stability and order in people's life (Giddens 1990; Bickerstaff and Simmons 2009). This occurs even though it means not adopting preparedness measures to reduce vulnerability to disaster. The anxiety overload contributes to building a collective memory where the disaster is anchored in the past, with little consideration of the role it could have for longer-term planning, including DRR. Although the risk of disaster remains present, it faces competing priorities that favor a sense of stability and economic boosts instead of preparedness and awareness raising. The conflicting needs contribute to explaining the challenges faced by efforts to learn lessons from the disaster and better implement disaster risk reduction measures.

In addition to the need for psychological recovery, absencing the risk of disaster is presented at a political level as a collective strategy to encourage investors, tourists, and immigrants to settle in Montserrat. A tour organizer, not specialized in volcano tours, explained in 2017 during an interview how decision makers aimed to dissuade her from too much focus on the volcano as a tourist attraction. She said the government did not want Montserrat being perceived as a risky place. This was confirmed during several interviews with policymakers in charge of tourism and several influential Montserratians, although all support efforts to memorializing the eruptions and the destroyed town of Plymouth. Several informants argued that tourists should also see the newly developed areas. In the same way, policymakers are reluctant to speak about the risk of disaster as they face pressure to reinvest in the exposed areas for various economic activities like tourism, sand mining, and geothermal energy production. These activities are crucial for the economy, but also for the legitimacy of elected people in their capacity to lead the recovery process. Memory is therefore built in an effort to rebuild a collective identity when the disaster is anchored in the past and where the future is stable.

Preparedness measures for volcanic hazards, that is, the consideration of risk of disaster, are regularly seen as controversial as they affect the Montserrat government's short-term economic objectives. For instance, in 2015, the government decided to temporarily extend the exclusion zone because of signs of increasing activity. This decision was met with large disagreement, in particular from the workers who lost income during that period due to the temporary closure of the quarries. The implementation of an exclusion zone and the displacement of the population to the north of Montserrat contribute to absencing the risk, by limiting it to a specific area that is uninhabited, although used for various activities. It enables the population, including policymakers, to feel safe, and removes the need for additional measures.

[Scientists] all say with reasonable certainty [...] we've seen the worst of it in terms of the scale of what it can do and such are the plans in place and the hazard zone system that it should never again, provided everybody observe those procedures [...] that's the volcano again should never be a threat to life. Everybody is now in the safe area. (A policymaker during a radio talk, in June 2017)

4.1.2.2 Risk Uncertainty Considering its psychological and social costs, efforts to build memory with the objective of preparedness to natural hazards are mainly justified by some level of risk certainty. In a post-disaster context, the perception of risk certainty may itself be influenced by the level of trauma and the level of psychological recovery of the affected population (Wachinger and Renn 2010).

In Montserrat, the way risk certainty affects preparedness measures is well illustrated by the comparison between risks associated with hurricanes and volcanic hazards. Although hurricanes do not affect Montserrat every year, there is a high level of certainty about their occurrence in the Caribbean region. Policymakers and disaster managers explain during interviews that each year, the preparedness period starts from February and they successfully mobilize all ranges of actors, from governments to churches and disaster management agencies. In contrast, since the last eruption in 2010, volcanic hazards present much more uncertainty regarding their occurrence. Although scientists and disaster managers regularly remind the residents that the volcano remains active, this discourse is confronted with the perception that volcanic risk is part of the past and not a concern for the future. Hence, preparedness measures for volcanic hazards do not appear as a priority, and very little is implemented other than the maintenance of an exclusion zone. A senior policymaker emphasized during a radio program in June 2017 the difficulties of implementing suitable measures: "Nobody can have an adequate plan for volcanic eruption because it's... the last one in Montserrat before this one was about 300 years ago and each eruption, each volcano is very different." He highlights not only the uncertainty in terms of the timing and possibility of occurrence but also the uncertainty in terms of efficiency of measures for disaster risk reduction.

The need for preparedness, and hence talks about volcanic risk, is also challenged by the strong desire to move 
forward rather than to remain in a state of perpetual readiness. That includes, for instance, reinvestment in some areas that were evacuated in 1997 - 1998 by the development of touristic and residential infrastructures. A policymaker also highlighted in January 2017 that people do not fear a potential eruption anymore, and the only active deterrent to going to the exclusion zone is the fear of sanctions. Residents, even well-informed people and law enforcement officials, provided evidence for this view by their own admission of incursions by night to the exclusion zone for fishing or hunting. Disaster managers also proved to be aware of the challenges of that position. One declared in January 2016: "people would like to think that the volcano is a past problem. Now they want to start something new." Here, the uncertainty of risk, in a context of trauma and fatigue, encourages the "absencing" of risk. This implies that memory construction is not led by the need to learn from the disaster and to prepare to volcanic risk, but mainly by the need to psychologically recover and to build a post-disaster identity. This strategy carries with it the risk of forgetting crucial knowledge learnt by experience that could be useful to cope with the impacts of future hazards.

\subsection{How is the Long-Term Recovery Process Affected?}

The way memory is constructed may have major implications for the long-term recovery process in the sense that it affects both the risk communication strategies and the economic and physical development initiatives.

\subsubsection{Interrupted Transfer of Knowledge}

The post-disaster recovery process, as a long-term process, is accompanied by demographic change. In Montserrat, it is marked both by the natural ageing of the population and by migration. In 2016 , the population was estimated to be composed of about $50 \%$ immigrants, compared to $10 \%$ in 1990 (before the eruption). Immigration intensified from 1998 , once the evacuation process was over, as the country needed to compensate for the emigration of $75 \%$ of the population. Demographic changes gradually led to a forgetting process (Connerton 2008), with the disaster being part of the past history of only a small part of the residents of Montserrat. As a result, a large proportion of residents have only a little, or no, experience of the eruption. Either because they were too young, because they were not born, or because they moved to Montserrat later, more than half of the residents of the island do not share the memory of the disaster. While sitting in a café that exhibits photos of the eruptions, we discussed the images with a group of five teenagers from different social groups (including two
Montserratians). Although they knew the general history, they had difficulties identifying in each photo what exactly could have happened and the extent of the hazards linked to the eruptions. In addition, they showed many signs of boredom and disinterest during that discussion. A Dominican woman also told me that although she knew that an eruption destroyed some villages, she had never gone to see the volcano and did not know the extent of the damaged area. This not only challenges the argument often expressed by policymakers during interviews that all residents remember the disaster, but this assumption also prevents the implementation of respectful and effective new ways of memorialization and efforts to support experience and knowledge transfers among the population.

The forgetting process is important given that little is done to transfer the memory of disaster from those who experienced the disaster to those who did not. Interviews show that the population believes that the responsibility to communicate about risk is on specific institutions, that is, disaster management agencies and governments. Yet at the time of the study, communication efforts related to risks linked to volcanic hazards are not prioritized by disaster management agencies and policymakers, other than the Montserrat Volcano Observatory. Between 2015 and 2017, several policymakers and disaster managers expressed doubts during interviews about the efficiency of risk communication efforts to reach the immigrant groups, in particular those who do not speak English. Although a large range of leaflets and a few radio programs have been translated into at least some of the languages spoken in the country, namely Spanish and Haitian, there has not been any assessment of their effectiveness in non-English speaking communities. Staff of two disaster management agencies explained during two interviews that although they created these leaflets, they have no certainty that people have read them, understand them, or even are aware of them.

Preparation for volcanic hazards is not a national priority, as the country faces more short-term and less uncertain risks. It is compounded by the fact that the volcanic eruption is not yet declared over officially but at the same time it is fully situated in the past by the population. Moreover, it also depends on the trust of the people in authority and in disaster management agencies. Scientists expressed concerns during an interview in 2016 about their credibility and capacity to maintain trust with the population, especially if no volcanic hazard occurs for a long period. In this context, memory is more vulnerable to forgetting and fading as demographic changes prevent stories being passed from one generation to another and from the original residents to the newcomers. Although the memorialization of the disaster mainly tends to anchor it in 
the past, there is a need to communicate about the persisting risks.

Returning memory, however, can play an important, but time-limited, role in preventing total forgetting of, and failure in learning from, disaster. Reminders regularly contribute to relaunch discussion and concern about the risk of disaster linked to volcanic hazards. For instance, a spontaneous increase in public comments in the street and online about the volcanic risk occurred when the smell of sulphur spread over the island because of particular wind conditions. In 2018, the publication of an article in the Guardian (UK) about the persisting risk of an eruption also reopened important questions and fears in the society, pushing volcanologists to clarify the level of risk (Ravilious 2018). The effects of these reminders are short-lived, however, and might become less and less important as time passes without major volcanic events. A volcanologist interviewed in 2016 explained that if people understand that the smell of sulphur is not linked to an increase of activity, it will gradually lose its reminder effect.

These observations raise important questions about the way risk and preparedness measures are discussed. Although the risk is an ongoing and changing phenomenon, it should perhaps be important to flag important events that should trigger preparedness campaigns or an increase in efforts to raise awareness. These communication activities should more carefully reflect the frequency and fluctuations in interest and should respond to the changing characteristics of the population.

In a context of ongoing risk, relying on collective memory of disaster that mainly aims to anchor the disaster in the past and to cope with the trauma prevents risk communication measures adapting to post-disaster changes, including demographic ones. The longevity of the crisis, with the persisting anxiety linked to risk, encourages forgetting efforts among society, enabling people to deal with anxiety and crisis fatigue. The challenge here is to preserve knowledge of emergency preparedness for longterm development, learnt during the past disaster, without raising anxiety for the short-term future.

\subsubsection{Gradual Reconstruction of Memory for a Sense of Stability}

Memory itself is not static and gradually evolves to follow specific needs and social pressures (Halbwachs and Coser 1992). It evolves for individuals and groups, being shaped by new realities and new needs. Because individuals cannot remember everything, information and data naturally fade away as time passes and as they seem irrelevant or useless (Muzaini 2015). There is therefore a risk that crucial knowledge, learnt from the experience of disaster, is altered or even forgotten.
This evolution is mainly visible through the gradual narrative changes when describing disaster. For instance, the ash falls that occurred during the volcanic crisis are generally described as very scary events because visibility was extremely limited. However, when interviewees are asked about the risks of reinvesting in the south, Montserratians tend to consider ash falls as something more annoying than dangerous. They mention the need to clean away the ash, but do not express worries about the danger of it. We can wonder if the change of narrative that people have for volcanic risk is conscious and corresponds to the absencing of the biggest constraints associated with the hazard as it belongs to the past (Halbwachs and Coser 1992). Indeed, by normalizing the risk and making it controllable, it seems to allow people to move on from the disaster and take action for redevelopment.

The forgetting process is also translated through the increasing pressure for reinvesting in the areas that were evacuated but not totally destroyed. Several policymakers explained that they face a growing pressure, especially from the older population who have a strong attachment to the abandoned lands, to reinvest in them as the volcanic activity remains quiet. In 2017, for the first time, a group of Montserratians led by a strong sense of nostalgia, organized a reunion of all the former inhabitants of Cork Hill, a village evacuated in 1997 . This event is particularly symbolic as it gathered both Montserratians who have remained on the island and Montserratians who have left. The diaspora especially maintains a very emotional relationship with the lost areas, with more difficulties in defining memories of Montserrat by its new features. Soon after this reunion, the Premier publicly commented in the Budget Statement (Romeo 2017):

The work of the Cork Hill Reunion Committee in organizing the reunion $[. .$.$] was an inspiration. [...]$ Therefore Cabinet has recently approved granting exemption from Import Duty and Consumption Tax for three years on all building materials imported specifically to repair or build any structure located in those villages of Cork Hill, Delvin's, Foxes Bay, Weekes's and Richmond Hill from the 1st of July. This will give direct support to those people who want to rebuild their homes and regenerate these important areas. The initiative will encourage significant construction activity in the private sector.

Although these areas are quite safe from volcanic hazards and their reinvestment would not considerably increase the vulnerability of the population to volcanic hazards, it testified to an evolution of mentality where the fear of volcanic hazards determines the decision making less and less. Collective memory is therefore shaped to respond to the strong sense of place and sense of nostalgia 
for the predisaster period. An active disaster-forgetting process is in place at the national level in order to encourage psychological recovery and economic development. Although the presence of the volcano is beneficial for tourism in the short term according to local policymakers and business owners, absencing the risk of disaster provides a sense of safety and stability in order to encourage investments and population growth. Yet absencing may prevent benefiting from the memory of the disaster to promote longer-term objectives of disaster risk reduction, via the reduction of vulnerability.

\section{Conclusion}

The recovery process is largely marked by the evolution of collective narratives about the past volcano disaster and the persisting risks. Remembering and forgetting have a strong influence on risk perception and hence on the willingness and ability of society to adopt informed preparedness measures. Less than a decade after the last volcanic activity in Montserrat, the disaster has become fully part of the identity of Montserrat, partly because of important efforts of memorialization. Memory construction, through the balance of reminded and forgotten elements, translates into a recovery process where different post-disaster needs may oppose each other.

In the case of Montserrat, memory construction is mainly led by the need for stability and certainty that has been generated by the extended and unfinished period of disruption. In this context, collective memory mainly anchors the disaster in the past rather than remind about the persistence of risk in the present and, therefore, about the need for knowledge transmission and risk communication. The search for stability and certainty, led by fatigue and the uncertainty of the occurrence of volcanic hazards, encourages the absencing of risks within collective narratives. This has crucial implications for the organic construction of memory in the sense that it makes remembering more vulnerable to fading and forgetting, especially in a context of rapid demographic changes. Postdisaster migrations and population ageing may indeed amplify and accelerate the forgetting process unless there are clear efforts to support risk communication and risk awareness. The learning process during the post-disaster recovery period is therefore largely affected by the active efforts for forgetting elements of the disaster and of risks, and by the natural evolution of memory. Forgetting may contribute to explain the reproduction of drivers of vulnerability despite a recent experience of disaster.

This research provides an important contribution about the role of memory and active forgetting about disaster during the critical post-disaster recovery process. While collective narratives contribute to how risk of disaster is understood, contributing to the transmission of knowledge and experience, risk perception and narratives themselves affect the construction of memory and its translation at the collective level. An essential question is whether there is a way to respect the recovery, and the image of recovery, while preserving preparedness for future possible activity. This research enables a better understanding of the motives for change and the obstacles and challenges for learning from a disaster about how to reduce vulnerability. There are therefore strong implications for making the post-disaster period an effective time for learning from that disaster crisis and preventing a reproduction of vulnerabilities.

Acknowledging that collective memory evolves and transforms itself may encourage implementation of effective measures to preserve and share experiences and lessons across generations and social groups in a way that supports increased disaster risk awareness. Moreover, recognizing the dilemma faced by authorities and disaster management agencies during a period with conflicting needs, fatigue, and poor psychological recovery, may encourage reframing of risk, and how to implement DRR measures. During the post-disaster recovery process, the collective unconscious effort to anchor the disaster in the past may be necessary and must be acknowledged. In practice, it may be useful to reframe how risk and disaster are understood by policymakers and disaster management agencies.

One of the highlighted challenges is how to remember the potential hazards closer to the volcano, particularly in those zones with low but finite risks from pyroclastic flows that are or about to be reoccupied. Considering the crisis as over (despite the ongoing status of the eruption) may allow risk management to play a continuing role as part of development strategies in the future. This strategy may allow reinvestment in the areas that have been affected (necessary for giving a sense of "normality"), while planning alternatives and increasing readiness for a future eruption. This compromise includes, for instance, planning evacuation routes, diversifying the response and recovery resources (in and out of the exclusion zone), and locating strategic infrastructure in safe areas.

Although this study does not give tangible solutions for disaster risk reduction in a post-disaster context, it promotes the acknowledgement of potential challenges for learning from a disaster, and hence increases the ability to counteract those obstacles. Because this study has focused on the case of volcanic hazards, specifically because of their high level of uncertainty and unpredictability, it would be interesting to pursue the study in a context where hazards occur more regularly in order to explore how remembering and forgetting efforts differ and how they are motivated. Such investigation also needs to be associated 
with research on effective risk communication and preparedness in post-disaster contexts.

Acknowledgements We express our gratitude to NERC (NE/ L002585/1) and the University of East Anglia for supporting and funding this research.

Open Access This article is licensed under a Creative Commons Attribution 4.0 International License, which permits use, sharing, adaptation, distribution and reproduction in any medium or format, as long as you give appropriate credit to the original author(s) and the source, provide a link to the Creative Commons licence, and indicate if changes were made. The images or other third party material in this article are included in the article's Creative Commons licence, unless indicated otherwise in a credit line to the material. If material is not included in the article's Creative Commons licence and your intended use is not permitted by statutory regulation or exceeds the permitted use, you will need to obtain permission directly from the copyright holder. To view a copy of this licence, visit http://creativecommons. org/licenses/by/4.0/.

\section{References}

Bickerstaff, K., and P. Simmons P. 2009. Absencing/presencing risk: Rethinking proximity and the experience of living with major technological hazards. Geoforum 40(5): 864-872.

Connerton, P. 2008. Seven types of forgetting. Memory Studies 1(1): 59-71.

Connerton, P. 2010. How societies remember. Cambridge: Cambridge University Press.

Conway, B. 2003. Active remembering, selective forgetting, and collective identity: The case of Bloody Sunday. Identity: An International Journal of Theory and Research 3(4): 305-323.

Convery, I., G. Corsane, and P. Davis. 2014. Displaced heritage. Responses to disaster, trauma and loss. Newcastle: Boydell \& Brewer.

Erll, A., and A. Nunning. 2008. Cultural memory studies: An international and interdisciplinary handbook. Berlin: De Gruyter.

Giddens, A. 1990. The consequences of modernity. Stanford: Stanford University Press.

Halbwachs, M. 1950. Space and the collective memory (La mémoire collective et l'espace). In The collective memory (La mémoire collective), ed. J. Halbwachs Alexandre, 83-105. Paris: Presses Universitaires de France (in French).

Halbwachs, M, and L.A. Coser. 1992. On collective memory. Edited, translated, and introduction by L.A. Coser. Chicago: University of Chicago Press.

Hamer, J.H. 1994. Identity, process, and reinterpretation. The past made present and the present made past. Anthropos 89(1-3): 181-190.

Hardt, O., K. Nader, and L. Nadel. 2013. Decay happens: The role of active forgetting in memory. Trends in Cognitive Sciences 17(3): $111-120$.

Hoelscher, S., and D. Alderman. 2004. Memory and place: Geographies of a critical relationship. Social \& Cultural Geography 5(3): 347-355.

Isakson, B.L., and G. Jurkovic. 2013. Healing after torture: The role of moving on. Qualitative Health Research 23: 749-761.

Jackson. M. 2002. The politics of storytelling. Variations on a theme by Hannah Arendt. Copenhagen: Museum Tusculanum Press.
Johnson, N.C. 2012. The contours of memory in post-conflict societies: Enacting public remembrance of the bomb in Omagh, Northern Ireland. Cultural Geographies 19(2): 237-258.

Kelman, I. 2020. Disaster by choice: How our actions turn natural hazards into catastrophes. Oxford: Oxford University Press.

Kevers, R., P. Rober, I. Derluyn, and L. de Haene. 2016. Remembering collective violence: Broadening the notion of traumatic memory in post-conflict rehabilitation. Culture, Medicine and Psychiatry 40(4): 620-640.

Le Blanc, A. 2012. Remembering disasters: The resilience approach. Journal of Art Theory and Practice 14: 217-245.

Legg, S. 2007. Reviewing geographies of memory/forgetting. Environment and Planning A 39(2): 456-466.

López-Carresi, A. 2013. Disaster management: International lessons in risk reduction, response and recovery. New York: Routledge.

McEwen, L., J. Garde-Hansen, A. Holmes, O. Jones, and F. Krause. 2017. Sustainable flood memories, lay knowledges and the development of community resilience to future flood Risk. Transactions of the Institute of British Geographers 42(1): 14-28.

Mika, K., and I. Kelman. 2019. Shealing: Post-disaster slow healing and later recovery. Area. https://doi.org/10.1111/area.12605.

Mileti, D.S. 1999. Disasters by design: A reassessment of natural hazards in the United States. Washington: Joseph Henry Press.

Monteil, C., P. Simmons, and A. Hicks. 2020. Post-disaster recovery and sociocultural change: Rethinking social capital development for the new social fabric. International Journal of Disaster Risk Reduction 42: Article 101356.

Montserrat Volcano Observatory and Disaster Management Coordination Agency. 2014. Montserrat hazard level system zonesversion 3 2-3. Flemmings, Montserrat: MVO and DMCA. https://mvoms.org/pub/Hazard_Level_System/HLS-20140801. pdf. Accessed 7 May 2020.

Muzaini, H. 2015. On the matter of forgetting and 'memory returns.' Transactions of the Institute of British Geographers 40(1): $102-112$.

Oliver-Smith, A., I. Alcántara-Ayala, I. Burton, and A. Lavell. 2016. Forensic Investigations of Disasters (FORIN): A conceptual framework and guide to research. Beijing: IRDR.

Olshansky, R.B., L.D. Hopkins, and L.A. Johnson. 2012. Disaster and recovery: Processes compressed in time. Natural Hazards Review 13(3): 173-178.

Parkhill, K., N.F. Pidgeon, K. Henwood, P. Simmons, and D. Venables. 2010. From the familiar to the extraordinary: Local residents' perceptions of risk when living with nuclear power in the UK. Transactions of the Institute of British Geographers 35(1): 39-58.

Pfefferbaum, B.J., D. Reissman, R.L. Pfefferbaum, R.W. Klomp, and R.H. Gurwitch. 2007. Building resilience to mass trauma events. In Handbook of Injury and Violence Prevention, ed. L. Doll, E.N. Haas, S. Bonzo, D. Sleet, and J. Mercy, 347-358. Boston: Springer US.

Ravilious, K. 2018. Terrawatch: Montserrat's volcano remains a risk. The Guardian, 6 March 2018. https://www.theguardian.com/ world/2018/mar/06/terrawatch-montserrats-volcano-remains-arisk\#comments. Accessed 5 May 2020.

Romeo, D. 2017. 2017-2018 budget statement. Moving Montserrat forward towards self-sustainability and inclusive economic growth. Plymouth (de jure) / Brades (de facto): Government of Montserrat. https://finance.gov.ms/wp-content/uploads/2017/06/ 2017-18-Budget-Statement.pdf. Accessed 5 May 2020.

SAC (Scientific Advisory Committee). 2013. Assessment of the hazards and risks associated with the Soufriere Hills Volcano, Montserrat. 18th report of the Scientific Advisory Committee on Montserrat. Part II, full report. Plymouth (de jure) / Brades (de facto): SAC. 
Singer, J.A., and M.A. Conway. 2008. Should we forget forgetting? Memory Studies 1(3): 279-285.

Suleiman, S.R. 2012. Crises of memory and the Second World War. Cambridge: Harvard University Press.

Wachinger, G., and O. Renn. 2010. Risk perception and natural hazards. CapHaz-Net WP3 report. Stuttgart: DIALOGIK NonProfit Institute for Communication and Cooperative Research.
Wachinger, G., O. Renn, C. Begg, and C. Kuhlicke. 2013. The risk perception paradox-Implications for governance and communication of natural hazards. Risk Analysis 33(6): 1049-1065.

Wilkinson, E. 2015. Beyond the volcanic crisis: Co-governance of risk in Montserrat. Journal of Applied Volcanology 4: Article 3.

Wisner, B., P. Blaikie, T. Cannon, and I. Davis. 2004. At risk: Natural hazards, people's vulnerability and disasters, 2nd edn. London: Routledge. 